\title{
Value Creation in Physical Asset Management: A Case Study
}

\author{
Damjan Maletič ${ }^{1, *}{ }^{\text {, Viktor Lovrenčić }}{ }^{2}$, Marta Grabowska ${ }^{3}$ and Matjaž Maletič ${ }^{1}$ \\ 1 University of Maribor, Faculty of Organizational Sciences, Kidriceva c. 55a, 4000 Kranj, Slovenia, Address; E-Mails: damjan.maletic@um.si; matjaz. \\ maletic@um.si \\ 2 C\&G d.o.o. Ljubljana, Riharjeva ulica 38, 1000 Ljubljana, Slovenia; E-mail: viktor.lovrencic@c-g.si; \\ 3 Poznan University of Technology, Piotrowo Street, No. 3, 60-965 Poznań, Poland; E-mail: marta.grabowska@put.poznan.pl
}

Abstract: Physical asset management (PAM) is an important part of any organization as it enables it to realize value from its assets. It focuses on optimizing the life cycle of assets, from conception through use, maintenance, decommissioning and disposal. The purpose of this paper is to present the implementation of the PAM practices. A case study methodology is used to provide insights into the implementation of the PAM practices, with a focus on the maintenance element of PAM. More specifically, it focuses on examining the application of the Value Driven Maintenance (VDM) methodology and its potential benefits for the company. Based on the results of the case study, it is argued that VDM as a methodology has the potential to support the practices of PAM by providing a tool to support the assessment of asset management, identification of potential cost savings, investment decision, etc. Finally, key observations are made to stimulate further studies in the field of PAM.

Keywords: physical asset management; maintenance; value driven maintenance; case study

\section{Introduction}

A rapidly changing business environment, strong competition, requirements to minimize losses are some of the conditions in which organizations work today [1]. This has led organizations to constantly look for new ways to improve performance and gain a competitive advantage. Over the past two decades, the demand for effective physical asset management (PAM) has steadily increased [2]. As a result, PAM has become an important area, especially in the capital-intensive industry [3-7]. Assets according to the ISO 55000 standard for asset management are items, things and entities which have a value or potential value to the organization [8]. Physical assets, also known as engineering assets, are important for creating tangible value for an organization in a wide range of industrial environments such as manufacturing, electricity supply, water supply, construction, mining, transportation services and various other sectors [9]. PAM begins with understanding the needs of the organization in line with its business objectives to deliver goods and services reliably, safely, on time and cost-effectively [10]. PAM strategy begins with the organization's strategy and plan for achieving its goals, and then supports delivery of the value associated with the organization's plan. However, ISO 55000 [8] does not contain any information on the approach to asset management, but merely provides the direction for elements for a management system (i.e. it characterizes a business system that is incidentally related to asset management), with a focus on value creation and risk management. Realizing the value from assets is a holistic approach that takes into account the complex expectations of stakeholders and provides the organization with competitive advantage. 
The internal effectiveness of the company is strong influenced by the maintenance role and the impact on other work areas such as production, quality, production costs, working environment, amount of work in progress and tied up capital [11]. To achieve world-class performance, more and more companies are making efforts to improve quality and productivity and reduce costs. In this context, effective maintenance is very important because it not only improves product quality, reduces production costs and productivity, but also increases the profitability of the organization [12]. The latter regards maintenance as a value driver. The contributions of maintenance to the success of organizations have been increasingly recognized [11]. However, the value cannot be realized through maintenance alone, it has to be realized together with operations and engineering, and top management has to define what is valuable to the organization. Although maintenance is an essential element of PAM, it is not sufficient and does not appear to be the intention of ISO 55000. In addition, traditional maintenance strategies, however, have often focused only on the maintenance phase and not on the entire life cycle of an asset [13].

PAM is therefore an approach that offers support in creating value throughout the entire asset life cycle. Different approaches/methodologies exists to support this view. Value Driven Maintenance (VDM), which is the focal point of this paper, is one of them. It supports companies to extract maximum economic value from an existing plant. In addition, VDM provides calculation models and industry specific benchmarks to determine the dominant value driver within the PAM [14].

Although there is a growing literature on various aspects of PAM (e.g. [5,15-18]), the topic PAM is relatively new from a scientific point of view. Further studies are therefore needed to examine various aspects such as the added value of maintenance and asset management. The purpose of this paper is therefore to present an implementation of VDM based on a case of a Slovenian company active in the field of electrical power transmission, and to discuss some key challenges of VDM implementation in relation to PAM.

\section{Theoretical background}

The scope of maintenance in the production environment can be seen from various definitions.
The British Standards Institute defines maintenance as a combination of all technical and associated administrative activities required to keep equipment, installations and other physical assets in the desired operating condition or restore them to this condition [19]. Furthermore, European standards covering the field of maintenance EN 13306:2017 [20] describe maintenance management as all activities of the management that determine the maintenance requirements, objectives, strategies and responsibilities, and implementation of them by such means as maintenance planning, maintenance control, the improvement of maintenance activities and economics. EN standard is broader in its definition because it also covers organizational activities that are indispensable for efficient and cost-effective maintenance. More recently, asset management comes to the forefront. It goes well beyond the scope of maintenance management. The asset management deals with the whole life cycle of the asset, from its design to its final disposal. ISO 55000 defines asset management as the coordinated activities of an organization to realize value from assets [8]. Although our study focuses on physical assets, it should be noted that asset management (AM) considers any type of asset that has an actual or potential value for the company. There is growing acceptance that the organization can benefits of formal asset management system (AMS) [21]. Further, prior research [4,5] showed that PAM delivers several organizational benefits, such as improved operational performance, enhanced financial performance, reduced costs, reduced waste, improved employee performance etc.

In addition, the following best practices of various international and European standards are proposed in relation to PAM, namely:

- ISO 21500:2012 Guidance on project management [22];

- ISO 16739:2018 Industry Foundation Classes (IFC) for data sharing in the construction and facility management industries [23];

- IEC 81346-2:2019 Industrial systems, installations and equipment and industrial products - Structuring principles and reference designations - Part 2: Classification of objects and codes for classes [24];

- EN 61355-1:2008 Classification and designation of documents for plants, systems and equipment [25];

- EN 13306:2017 Maintenance - Maintenance terminology [20];

- EN 13269:2016 Maintenance - Guideline on preparation of maintenance contracts [26];

- EN 13460:2009 Maintenance - Documentation for maintenance 
[27];

- EN 15331:2011 Criteria for design, management and control of maintenance services for buildings [28];

- EN 15341:2019 Maintenance - Maintenance Key Performance Indicators [29];

- EN 15628:2014 Maintenance - Qualification of maintenance personnel [30];

- EN 16646:2014 Maintenance - Maintenance within physical asset management [31].

2.1 Physical asset management and value driven maintenance

PAM should be seen as a holistic approach to managing assets, as it is much broader in scope and has many more dimensions than asset maintenance [18]. In essence, effective PAM requires an interdisciplinary approach, where synergies should exist between traditional disciplines such as accounting, engineering, finance, humanities, logistics and information systems technologies [32]. However as mentioned above maintenance is an essential element of PAM. VDM supports organizations in managing the maintenance process with regard to the requirements of PAM [14]. Haarman and Delahay [14] therefore emphasize the importance of maintenance and asset management in their book VDMXL, the updated version of VDM. As such, VDMXL explains how a combination of maintenance, lifetime extension and modernization can increase the maximum economic value of an existing plant, fleet or infrastructure. The VDM extension of VDMXL results from the extension of the service life of industrial plants. It should be noted that VDMXL is modeled in close cooperation with industry. Most experience and knowledge comes from the infrastructure sector (e.g. rail, water, energy, ports, roads, bridges, etc.). These companies focused much more than others on managing the life cycle of assets. The authors found that maintenance has evolved over time in the field of PAM. The main difference is that maintenance workers are responsible for operating costs (OPEX - operating expenses) and asset managers are responsible for investment costs (CAPEX - capital expenditures).

VDM calculates the net present value, enables the evaluation of various options, the selection of suitable solutions and the creation of an optimal maintenance organization. According to VDM, four maintenance factors are identified that influence the value of the company, namely asset utilization, resource allocation, cost control and HSE (health, safety and environment) [14,33]. These four drivers are used to calculate the value of the maintenance strategy using the discounted present value (DPV) formula. However, a maintenance performance measurement system (MPM) is needed to build knowledge of the four drivers and to estimate the DPV. The European Standard on Key Performance Indicators (KPIs) for Maintenance EN 15341:2019 [29] provides a set of indicators for this purpose. However, due to the ratio-based structure of the indicators, even the most general indicators of the standard can be difficult to implement in an organization without prior experience in data collection and analysis. The most essential and easiest to implement indicators are therefore those found in the numerators and denominators of the European standard's KPIs [33].

Haarman and Delahay [14] predict that the development of PAM has increased interest in the ISO 55000 standard. They also argue that the VDMXL practice can go one step further. They believe that the ISO 55000 prescribes what we need to do, but the VDMXL explains how the process must be managed to achieve the highest economic value in approving the maintenance process, such as scheduling, execution, inventory management and tools. So we need to position VDMXL as a maintenance model and both as a PAM model. VDM is defined by four basic factors that influence the value of the company, namely (Figure 1): asset utilization, resource allocation, cost control and HSE (health, safety and environment).

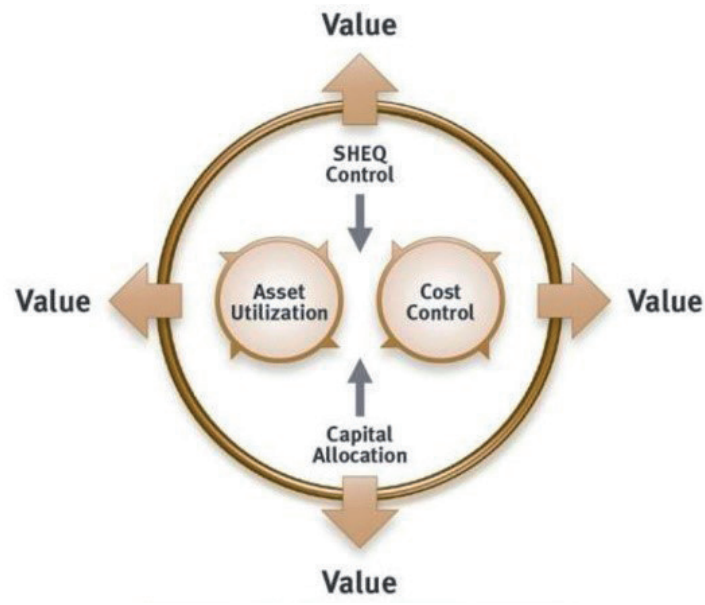

Figure 1: Model of Value Driven Maintenance [14].

VDM makes it possible to bridge the barrier between the maintenance sector and top 


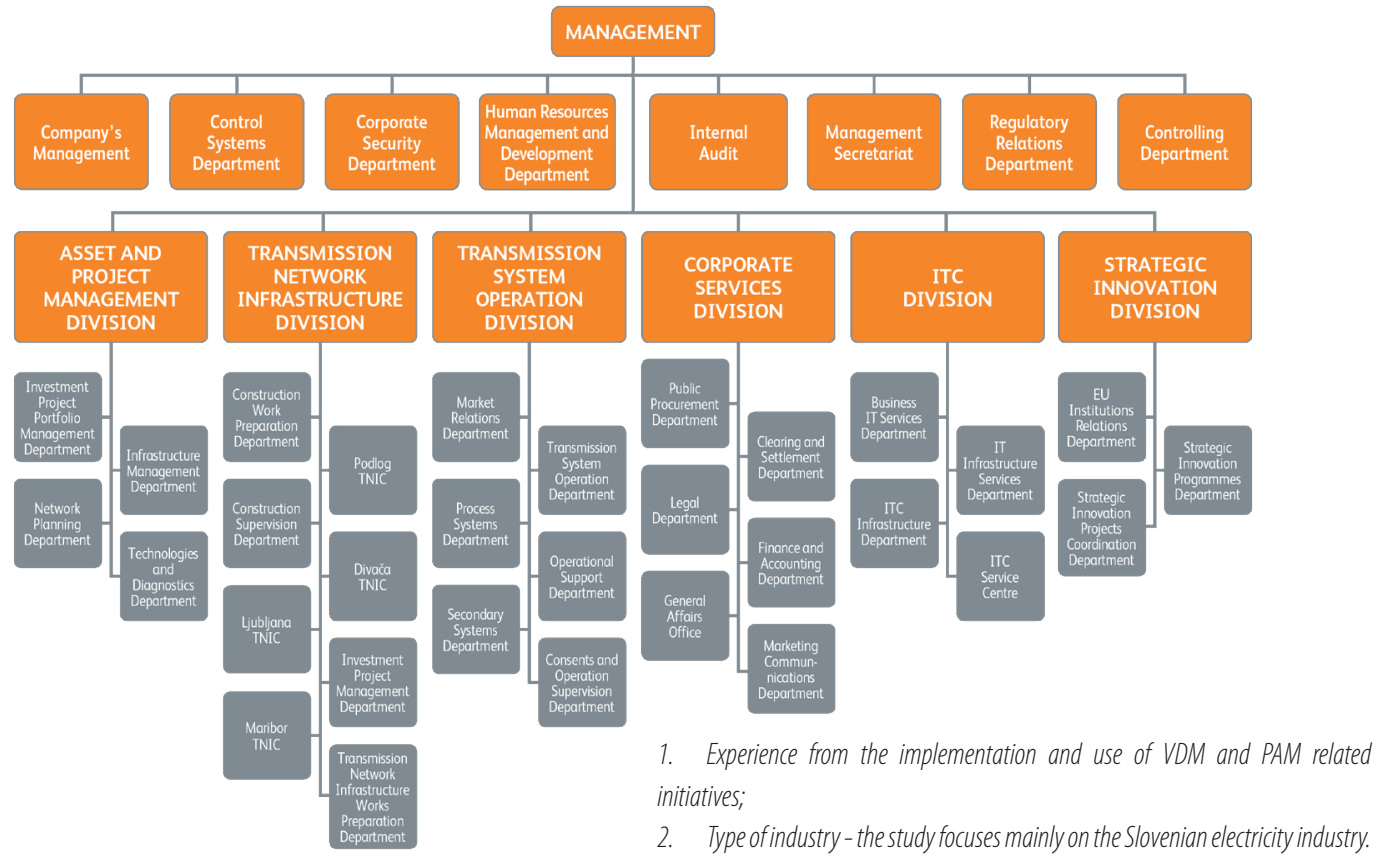

Figure 2: Organizational structure of the company ELES.

management, and offers a good opportunity for broader practical use. However, the implementation and use of this concept is quite complex and requires an appropriate project approach.

\section{Research methods}

The paper uses a case study approach with a focus on the Slovenian company ELES. ELES is the operator of Slovenia's electric power transmission network. Therefore, a case study approach was used in this paper to provide insights into the phenomenon under investigation [34]. The main reason for using a qualitative approach was the argument that PAM is a relatively new phenomenon and that a comprehensive theory is still lacking. In this study, VDM implementation is examined in detail on the basis of a single case. The researchers (e.g. [35]) have addressed the question of a single case study. While several studies generally provide a stronger basis for theory formation [34], it has been shown that single case studies can richly describe the existence of a phenomenon [36].

The selection of the appropriate organization was primarily based on what could be learned in relation to the purpose of the study. The following criteria were primarily considered in the selection process:

\section{A case study of value driven maintenance (VDM) implementation}

Given the complexity of the issue, it must first be emphasized that the Slovenian development plan for the distribution system includes the strategy of product life cycle management [37]. Based on the strategic directions and PAM policy, ELES has developed a modern concept of PAM that incorporates the principles of the relevant standards and the best practices of European distribution system operators. The organizational structure of the ELES is shown in Figure 2.

ELES has introduced several standards in order to meet the different requirements, in particular with regard to quality management, environmental management, occupational health and safety management, information security, asset management, etc. The ELES has determined that a prerequisite for an efficient integration management system is appropriate information support. During the transition process to the VDM, ELES changed the organizational structure and developed an autonomous unit for related to PAM. The latter was an essential factor for the management of maintenance processes and for a better definition of key roles and responsibilities.

\subsection{Information support}

Immediate and fast access to information is 
becoming one of the most important elements for successful maintenance operations. The first stage of the development of maintenance information support in ELES was the development of a database with technical data for electro-energetic equipment. During the following phases of IS support for maintenance (in 2004), ELES decided to implement IBM Maximo. Currently, IBM Maximo, as a support for maintenance information, is closely integrated with the new ERP (Enterprise Resource Planning) business system, namely MS Dynamics AX. Recently, ELES has started to establish the integration between IBM Maximo and the geographic information system (GIS) and the integration of few other maintenance software applications with GIS. The digitization at ELES is focused on the integration of different systems and the analytical online processing of maintenance data. The aim of this development is to reduce maintenance costs and to support the process of investment decisions for the distribution network. For this purpose, tools for condition monitoring and data visualization are considered from the perspective of efficient maintenance and PAM, including the VDM methodology [38].

The support of maintenance information is based on the following requirements and instructions from ELES $[37,38]$ :

- The use of the new functionality of IBM Maximo (e.g. Maximo Linear Asset Management, Maximo Spatial Asset Management, Maximo ITIL);

- Improving access to spatial data;

- To improve the quantity and quality of information;

- Improving the integration of different information systems (e.g. PSA, GSM);

- Mobile access to required information at a physical location;

- To improve the communication between loT applications;

- The introduction of new maintenance methods and concepts aimed at reducing costs (e.g. RCM - Reliability Centered Maintenance, VDM);

- The use of modern analytical processing tools (e.g. Asset Health Indices);

- The introduction of new technologies (3D visualization, maintenance drones, etc.).

ELES has set up the Diagnostic Analytics Center to support efficient PAM. These activities are part of the ELES strategy to achieve its objectives:

- Efficient support for PAM, maintenance and investment management;

- Evaluation of the product life cycle;

- Monitoring the technical condition of the equipment;

- Integration of the current technical information systems;
- More efficient planning of maintenance processes;

- More efficient resource planning/allocation for maintenance processes;

- Technical-economic analyzes and statistics in the field of use, recycling and quality of equipment;

- Preparation of appropriate reports.

The long-term goal of ELES is to achieve synergy between the company's systems/services in order to provide efficient decision support in an ever-changing business environment. New ERP and Maximo are two important elements in this context, building a bridge between the business and technical aspects of operations. It is argued that Business Intelligence (BI) is an important aspect of business life and represents a set of concepts/ methods aimed at improving decision-making processes, especially based on real life data. BI enables the collection of large amounts of data from different sources. It is essential that BI supports data integrity and standardization, especially considering the different subsystems (MDM Master Data Management). High quality, timely and comprehensive information is essential to support the decision making process in ELES. The aim of ELES is to build the platform for BI in the coming years, including the self-service and enterprise level. In addition, ELES also facilitates the use of different approaches (e.g. OLAP cube, reporting services, dashboards, Big Data, etc.).

In addition, ELES aims to transfer its data warehouse to a new technological platform (Microsoft) in order to provide a better user experience, enable advanced functionalities and integrate organization-wide business aspects into the annual reporting system.

The strategic objective of ELES is to extend the software applications by updating the current technical information systems (TIS). For example, with the introduction of the Asset Health Index or through the integration of TISs as well as through the introduction of new PAM tools and methods (e.g. VDM). Against this background, ELES strives to ensure the long-term efficiency of its assets by providing timely, reliable and efficient services to users and other stakeholders. Efficient PAM considers quality, risks, benefits and costs throughout the entire life cycle of the assets. ELES focuses on the safe, reliable, sustainable and environmentally friendly fulfillment of grid users' requirements.

It should be emphasized that ELES has a strong 
strategic focus on PAM [39]. In this context, the project initiative was taken to start the development of the VDM application in ELES. ELES has started the implementation of VDM in 2016. At the end of 2016, the VDM project was in the test phase, comprising eleven KPIs. VDM is applied via control panels in the form of KPIs, graphs, tables showing the status of key parameters (e.g. KPI - cost control, work planning, maintenance execution, outsourcing, use of equipment, health and safety at work, environment, reliability, spare parts management, training, documentation, etc.). From 2017 the system is used in the production environment. The data warehouse includes all data from 2015.

The application of VDM in ELES is based on data collected from various sources, processed and stored in unified data warehouse. As mentioned above, the control panel is a key to presenting KPIs for 12 different areas that have a potential impact on PAM performance. These areas are [40]:

- Control of maintenance costs by considering the relationship between maintenance costs and the estimation of the replacement value of assets;

- Asset deterioration, which is represented by the ratio between actual operating time and available time (asset availability);

- Asset portfolio management, which is represented by the relationship between actual asset age and planned technical life of assets;

- Investment costs, which are represented by the relationship between investment costs and replacement costs;

- Ratio of preventive maintenance costs to total maintenance costs;

- Planning, which includes monitoring the realization/progress of maintenance activities;

- Utilization rate, which is represented by the ratio between the time spent on maintenance activities and full working time;

- Outsourcing cost control, which is performed and demonstrated by the ratio of outsourcing costs to total maintenance costs;

- Employee training, which is represented by the proportion of employee training costs;

- Control of health and safety, environmental and quality costs;

- Spare parts costs, represented by the relationship between the cost of spare parts inventory and asset replacement value;

With regard to the above-mentioned required data, it is important to ensure data quality. From this perspective, the relationship between the amount of data collected and the amount of all data to be collected and stored in the database is presented. The VDM application allows visualization (e.g. graphics) for each field measured by KPIs. The advanced options are also available, namely data filtering taking into account the maintenance location, organizational units, timeline, type of activities, etc.

\section{Concluding remarks}

This paper focuses on PAM, especially focusing on maintenance as part of PAM and the challenges facing today's organizations in managing assets. This is particularly important for the Slovenian Electricity Transmission System Operator (ELES), which wants to ensure the safe, reliable and uninterrupted transmission of electricity. Part of the company's strategy was to introduce Value Driven Maintenance (VDM) to further improve the level of maintenance and PAM activities.

It has been shown that VDM is a method of corporate management that aims to derive the greatest benefit from a company's PAM efforts. As

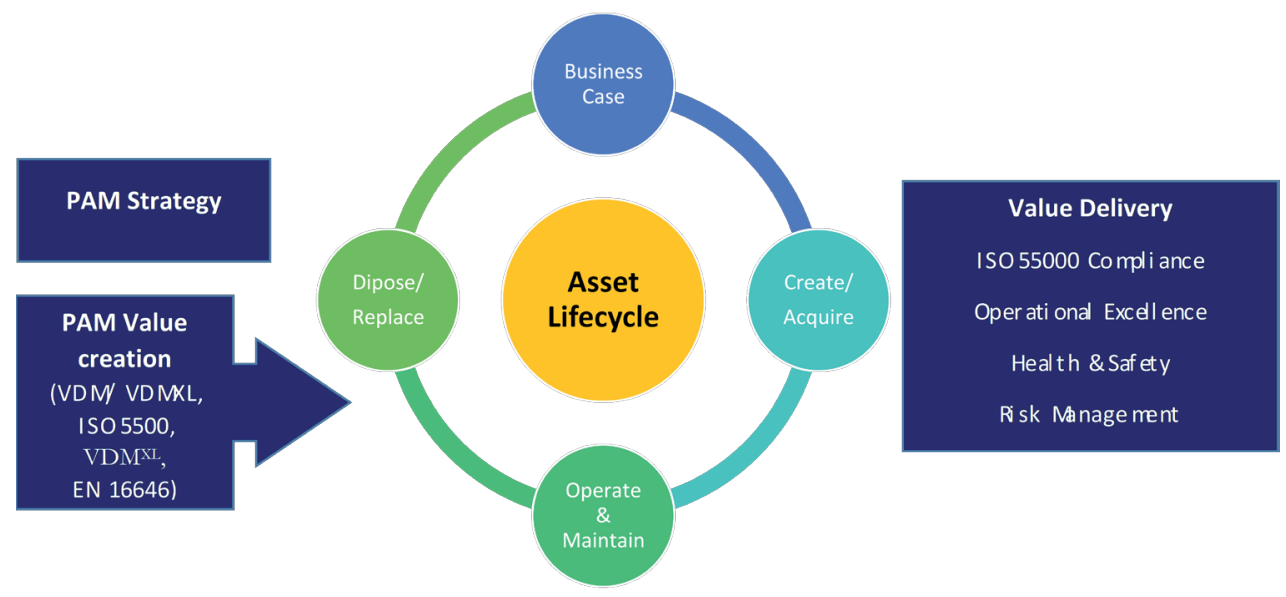

Figure 3: Conceptual framework for PAM value creation. 
a case study shows, the VDM application focuses on several areas among which we can highlight the performance evaluation of PAM, the effectiveness of resource allocation, the company's health, safety and environmental performance (SHE), the control and reduction of maintenance costs, etc. VDM could be seen from the perspective of effective management of the life cycle of assets that provide value to all stakeholders.

Based on the results of the case study and the literature review, a conceptual framework is provided as shown below (Figure 3).

It is argued that the company needs to develop a PAM strategy that integrates different solutions to achieve the desired PAM goals. This framework may inspire further studies that investigate the interaction between PAM and VDM.

\section{References and Notes}

[1] Pačaiová, H., Sinay, J., and Nagyová, A. (2017). Development of GRAM - A Risk Measurement Tool Using Risk Based Thinking Principles, Measurement, 100, pp. 288-296.

[2] Wijnia, Y., and de Croon, J. (2015). The Asset Management Process Reference Model for Infrastructures," 9th WCEAM Research Papers, J. Amadi-Echendu, C. Hoohlo, and J. Mathew, eds., Springer International Publishing, Cham, pp. 447-457.

[3] Komonen, K., Kortelainen, H., and Räikkönen, M. (2012). Corporate Asset Management for Industrial Companies: An Integrated Business-Driven Approach, Asset Management: The State of the Art in Europe from a Life Cycle Perspective, T. Van der Lei, P. Herder, and Y. Wijnia, eds., Springer Netherlands, Dordrecht, pp. 47-63.

[4] Maletič, D., Maletič, M., Al-Najjar, B., and Gomišček, B. (2018). Development of a Model Linking Physical Asset Management to Sustainability Performance: An Empirical Research, Sustainability, 10(12), p. 4759.

[5] Maletič, D., Maletič, M., Al-Najjar, B., and Gomišček, B. (2020). An Analysis of Physical Asset Management Core Practices and Their Influence on Operational Performance, Sustainability, 12(21), p. 9097

[6] Gavrikova, E., Volkova, I., and Burda, Y. (2020). Strategic Aspects of Asset Management: An Overview of Current Research, Sustainability, 12(15), p. 5955.

[7] Lima, E. S., McMahon, P., and Costa, A. P. C. S. (2020). Establishing the Relationship between Asset Management and Business Performance, International Journal of Production Economics, p. 107937.

[8] ISO 55000:2014 (2014). Asset Management - Overview,
Principles and Terminology, International Organization for Standardization (ISO), Geneva, Switzerland.

[9] de Almeida, N. M., Vieira, J., Silva, J. G., and e Castro, C. (2021). The Impact of Asset Management Development Programs in Infrastructure Organizations, Sustainability and Automation in Smart Constructions, H. Rodrigues, F. Gaspar, P. Fernandes, and A. Mateus, eds., Springer International Publishing, Cham, pp. 247-258.

[10] Chattopadhyay, G. (2021). Asset Management Journey for Realising Value from Assets, Handbook of Advanced Performability Engineering, K.B. Misra, ed., Springer International Publishing, Cham, pp. 429-450.

[11] Al-Najjar, B. (2007). The Lack of Maintenance and Not Maintenance Which Costs: A Model to Describe and Quantify the Impact of Vibration-Based Maintenance on Company's Business, International Journal of Production Economics, 107(1), pp. 260-273.

[12] Maletič, D., Maletič, M., Al-Najjar, B., and Gomišček, B. (2014). The Role of Maintenance in Improving Company's Competitiveness and Profitability: A Case Study in a Textile Company, Journal of Manufacturing Technology Management, 25(4), pp. 441-456.

[13] Liyanage, J. P., and Badurdeen, F. (2010). Strategies for Integrating Maintenance for Sustainable Manufacturing, Engineering Asset Lifecycle Management, D. Kiritsis, C. Emmanouilidis, A. Koronios, and J. Mathew, eds., Springer, London, pp. 308-315.

[14] Haarman, M., and Delahay, G. (2016). VDMXL: Value Driven Maintenance \& Asset Management, Www. vdmxl.com.

[15] Komljenovic, D., Gaha, M., Abdul-Nour, G., Langheit, C., and Bourgeois, M. (2016). Risks of Extreme and Rare Events in Asset Management, Safety Science, 88, pp. 129-145.

[16] Trindade, M., Almeida, N., Finger, M., and Ferreira, D. (2019). Design and Development of a Value-Based Decision Making Process for Asset Intensive Organizations, Asset Intelligence through Integration and Interoperability and Contemporary Vibration Engineering Technologies, J. Mathew, C.W. Lim, L. Ma, D. Sands, M.E. Cholette, and P. Borghesani, eds., Springer International Publishing, Cham, pp. 605-623.

[17] Schuman, C. A., and Brent, A. C. (2005). Asset Life Cycle Management: Towards Improving Physical Asset Performance in the Process Industry, International Journal of Operations \& Production Management, 25(6), pp. 566579.

[18] Amadi-Echendu, J. E., Willett, R., Brown, K., Hope, T., Lee, J., Mathew, J., Vyas, N., and Yang, B.-S. (2010). What Is Engineering Asset Management?, Definitions, Concepts and Scope of Engineering Asset Management, J.E. AmadiEchendu, K. Brown, R. Willett, and J. Mathew, eds., Springer, 
London, pp. 3-16.

[19] BSI 3811:1984 (1984). Glossary of Maintenance Terms in Terotechnology, British Standard Institution (BSI), London.

[20] EN 13306:2017 (2017). Maintenance - Maintenance Terminology, CEN EN - European committee for standardization.

[21] Alsyouf, I., Alsuwaidi, M., Hamdan, S., and Shamsuzzaman, M. (2018). Impact of ISO 55000 on Organisational Performance: Evidence from Certified UAE Firms, Total Quality Management \& Business Excellence, pp. 1-19.

[22] ISO 21500:2012 (2012). Guidance on Project Management, International Organization for Standardization (ISO) Geneva, Switzerland.

[23] ISO 16739:2018 (2018). Industry Foundation Classes (IFC) for Data Sharing in the Construction and Facility Management Industries, International Organization for Standardization (ISO), Geneva, Switzerland.

[24] IEC 81346-2:2019 (2019). Industrial Systems, Installations and Equipment and Industrial Products - Structuring Principles and Reference Designations - Part 2: Classification of Objects and Codes for Classes.

[25] EN 61355-1:2008 (2008). Classification and Designation of Documents for Plants, Systems and Equipment.

[26] EN 13269:2016 (2016). Maintenance - Guideline on Preparation of Maintenance Contracts, CEN EN - European committee for standardization.

[27] EN 13460:2009 (2009). Maintenance - Documentation for Maintenance, CEN EN - European committee for standardization.

[28] EN 15331:2011 (2011). Criteria for Design, Management and Control of Maintenance Services for Buildings, CEN EN - European committee for standardization.

[29] EN 15341:2019 (2019). Maintenance - Maintenance Key Performance Indicators, CEN EN - European committee for standardization.

[30] EN 15628:2014 (2014). Maintenance - Qualification of Maintenance Personnel, CEN EN - European committee for standardization.

[31] EN 16646:2014 (2014). Maintenance - Maintenance within Physical Asset Management., CEN EN - European committee for standardization.

[32] Frolov, V., Ma, L., Sun, Y., and Bandara, W. (2010). Identifying Core Functions of Asset Management, Definitions, Concepts and Scope of Engineering Asset Management, J.E. AmadiEchendu, K. Brown, R. Willett, and J. Mathew, eds., Springer, London, pp. 19-30.

[33] Stenström, C., Parida, A., Kumar, U., and Galar, D. (2013). Performance Indicators and Terminology for Value Driven Maintenance, Journal of Quality in Maintenance Engineering, 19(3), pp. 222-232.
[34] Yin, R. (2009). Case Study Research: Design and Methods, Sage Publications, Thousand Oaks CA.

[35] Eisenhardt, K. M., and Graebner, M. E. (2007). Theory Building From Cases: Opportunities And Challenges, Academy of Management Journal, 50(1), pp. 25-32.

[36] Siggelkow, N. (2007). Persuasion With Case Studies, Academy of Management Journal, 50(1), pp. 20-24.

[37] ELES (2019). Razvojni Načrt Prenosnega Sistema Republike Slovenije Od Leta 2019 Do Leta 2028.

[38] Tomažič, R., Polajner, A., and Kozjek, D. (2016). Informacijska Podpora Vzdrževanju v Družbi ELES, Slovenska Konferenca o Vzdrževanju Elektroenergetskih Objektov. Nova Gorica: Slovensko Združenje Elektroenergetikov CIGRE-CIRED.

[39] Lovrenčić, V. (2018). The Impact of Live Working as a Maintenance Method for Electrical Installations, PhDThesis, Faculty of Organizational Sciences, University of Maribor.

[40] Tomažič, R., Polajner, A., and Kozjek, D. (2017). Informacijska Podpora Upravljanju s Sredstvi v ELES-u, Proceedings of 13. Konferenca Slovenskih Elektroenergetikov. Maribor: Slovensko Združenje Elektroenergetikov CIGRE-CIRED. 